\title{
The knowledge, attitude, and practice of physicians and medical students of Rafsanjan University of Medical Sciences, Iran, regarding standard precautions
}

\begin{abstract}
Asadpour $\mathrm{M}, \mathrm{PhD}^{1}$, Vazirinejad $\mathrm{R}, \mathrm{PhD}^{* 2}$, Esmaeili $\mathrm{A}, \mathrm{PhD}^{3}$, Bazyar Sh, $\mathrm{MD}^{4}$, Fallah A, $\mathrm{MSc}^{5}$

1-Assistant Prof., Dept. of Health Promotion and Health Services, School of Medicine, Rafsanjan University of Medical Sciences, Rafsanjan, Iran. 2- Professor of Epidemiology, Dept. of Social Medicine, Occupational Environmental Research Center, Rafsanjan University of Medical Sciences, Rafsanjan, Iran. 3- Assistant Prof., Dept. of Social Medicine, Occupational Environmental Research Center, Rafsanjan University of Medical Sciences, Rafsanjan, Iran 4- General Physician, Rafsanjan University of Medical Sciences, Rafsanjan, Iran. 5- MSc of Epidemiology, Dept. of Social Medicine, Rafsanjan University of Medical Sciences, Rafsanjan, Iran.
\end{abstract}

$\begin{array}{lll}\text { Abstract } & \text { Received: June 2014, Accepted: February } 2015\end{array}$

Background: Physicians and medical students are at risk of exposure to a broad range of viral pathogens through percutaneous injury, contact of mucous membrane with blood, and other potentially infectious body fluids. The objective of this study was to determine the knowledge, attitude, and practice (KAP) of physicians and medical students of Rafsanjan University of Medical Sciences, Iran, regarding standard precautions.

Materials and Methods: This was a cross-sectional research based on a survey performed in 3 teaching hospitals affiliated with Rafsanjan University of Medical Sciences. Data were collected using a self-administered structured questionnaire. Subsequently, researchers distributed the questionnaires among the individuals who agreed to participate in the study. The participants were given instructions on completing the questionnaires. After completion of the questionnaires, they were collected and statistically processed with SPSS software using frequencies, percentages, the averages and standard deviations, and the independent ttest. All P values equal to or less than 0.05 were considered as statistically significant.

Results: The response rate in this study was $95 \%$. The mean age of subjects was $27.6 \pm 5.3$ years. The majority of subjects were female $(62.1 \%)$, single $(66.3 \%)$, and medical interns (78.9\%). Most subjects were untrained on standard precautions $(64.5 \%)$. The mean and standard deviations of KAP scores were $37.6 \pm 7.4$ (out of 46), $32.6 \pm 4.5$ (out of 45), and $33.06 \pm 6.5$ (out of 44), respectively. The independent t-test showed significant differences between knowledge and practice scores and marital status. It also showed significant differences between the practice score and training on standard precautions $(\mathrm{P}<0.05)$.

Conclusions: The results showed that the knowledge score was desirable, but the attitude and practice scores were not desirable. Thus, educational programs with the foundation of bloodborne infections, infection control, safety recommendations, and different aspects of standard precautions are recommended.

Keywords: Physicians, Medical Student, Knowledge, Attitudes, Precautions

\section{Introduction}

Hospital infections (HIs) can arise through the spreading of microorganisms, through personal hands, equipment, patient's blood, body fluid, secretions, and/or used solutions (1-3). Nosocomial infections, His, or health care-associated infections, are a serious problem in the healthcare services as they are common causes of illness and mortality among hospitalized patients (4,5). Physicians and medical students are at risk of hospital-acquired viral infections and exposure to a broad range of viral pathogens, including hepatitis $B$ virus (HBV), hepatitis C virus

\footnotetext{
* Corresponding author: Reza Vazirinejad, Dept. of Social Medicine, Rafsanjan University of Medical Sciences, Rafsanjan, Iran. Email: rvazirinejad@yahoo.co.uk
} 
(HCV), and human immunodeficiency virus (HIV), through percutaneous injury (e.g., needle stick and cut with a sharp object), contact of mucous membrane or nonintact skin with blood, tissue, or other potentially infectious body fluids (6).

After recognizing this threat, the United States Centers for Disease Control and Prevention (CDC) proposed a series of procedures for preventing occupational exposures, reducing the risk of transmission of blood-borne pathogens (BBPs), and handling potentially infectious materials such as blood and body fluids. These procedures are known as standard precautions (SPs) (6-8).

According to the SPs regulations, patient blood, body fluid, secretions, and excrement have infectivity, and thus, have an effect on both patients and medical staff. SPs include regular personal hygiene, hand washing, performing sterilization, and the safe removal of sharp instruments, handling and disposal of needles, sharp things, and use of protective barriers and personal protection equipment such as gloves, gown, face shields, and eye protection gear whenever there is contact with mucous membranes, blood, and body fluids of patients, and appropriate disposal of sharp instruments, body fluids, and other clinical wastes (3, 5, 7, 9, 10).

The HBV, HCV, and HIV infections are considered as a serious health problem worldwide $(11,12)$. The World Health Organization (WHO) estimates that about 3 million health care workers (HCWs) face occupational exposure to blood-borne viruses each year, and $90 \%$ of the infections occur in low income countries $(7,13)$. Some Reports indicate that SPs are effective in preventing both occupational exposure incidents and their associated infections $(5,8)$. Surveillance and followup of HCWs' compliance to SPs is an essential factor of occupational infection control as it enables assessment of risks of occupational exposure to infection and research programs are currently being performed on SPs regulations in many countries (7, 14-16).

Many studies have demonstrated that knowledge, attitude, and practice (KAP) of HCWs regarding the risk factors related to needle stick injuries (NSIs), use of preventative measures, and agreement with SPs, routes of spreading of HBV and $\mathrm{HCV}$ are insufficient and unsatisfactory $(10,17,18)$. Consequently, the field of SPs has attracted increasing attention from all medical workers, and research programs are currently being performed on SPs regulations in many countries.

Therefore, the objectives of this study were to assess the rate of KAP of physicians and medical students of Rafsanjan University of Medical Sciences, Iran, regarding SPs.

\section{Materials and Methods}

This was a cross-sectional research based on a survey on 100 physicians and medical students in 3 teaching hospitals affiliated to Rafsanjan University of Medical Sciences. Data were collected using a selfadministered structured questionnaire which comprised of 4 main sections including demographic variables, and KAP of physicians and medical students regarding SPs. The validity and reliability of the questionnaire were measured using content validity and Cronbach's alpha coefficient, respectively.

The mean knowledge of SPs was measured with the use of 23 items with 3 answer choices (true, false, and I do not know); 2 points for a correct answer, 0 for wrong answers, and 1 point was considered for not knowing (scores ranged from 0 to 46). The mean attitude toward the SPs was measured with the use of 9 items with 5-point Likert scale (completely disagree, disagree, disagree a little, agree a little, agree, completely 
agree). To the completely agree answer 6 points was given and completely disagree received only 1 point (scores ranged from 9 to 45). The mean practice of the SPs was measured with the use of 11 items with 4 answer choices (never, sometimes, many times, always); where the answer was completely agree 6 points was given and completely disagree 1 point. Scores ranged from 11 to 44. A higher score means a higher KAP of the SPs.

Subsequently, researchers visited subjects and distributed the questionnaires among those who agreed to participate in the study. They were given instructions on completing the questionnaires. A total of 100 questionnaires had been distributed. After their completion, the questionnaires were collected.

Collected data were statistically processed using SPSS software (version 16, SPSS Inc., Chicago, IL, USA). Frequencies and percentages of the demographic variables of the participants, and the averages and standard deviations of the scores of knowledge, attitude, and practice of SPs were obtained. The independent t-test was used to analyze the scores of KAP of SPs by demographic variables of the subjects. All $\mathrm{P}$ values equal to or less than 0.05 were considered statistically significant.

\section{Results}

In the present study, 100 questionnaires were distributed among the samples and 95 of them were completed and returned and had faithful responses (response rate of $95 \%)$. The mean age of subjects was $27.6 \pm 5.3$ years. The majority of samples were female $(62.1 \%)$, single $(66.3 \%)$, and medical interns $(78.9 \%)$. In addition, most subjects were untrained on SPs $(64.5 \%)$ (Table 1).

Table 1: Distribution of samples by age, gender, marital status, occupation, and training on SPs

\begin{tabular}{|c|c|c|}
\hline Variable & Answer & Number (\%) \\
\hline \multirow{4}{*}{ Age } & $<26 \mathrm{y}$ & $46(50)$ \\
\cline { 2 - 3 } & $26-30 \mathrm{y}$ & $30(32.6)$ \\
\cline { 2 - 3 } & $31-35 \mathrm{y}$ & $5(5.4)$ \\
\cline { 2 - 3 } & $36-40 \mathrm{y}$ & $8(8.7)$ \\
\cline { 2 - 3 } & $>40 \mathrm{y}$ & $3(3.3)$ \\
\cline { 2 - 3 } & Missing & $3(3.3)$ \\
\hline \multirow{2}{*}{ Gender } & Male & $36(37.9)$ \\
\cline { 2 - 3 } & Female & $59(62.1)$ \\
\hline \multirow{2}{*}{ Marital status } & Single & $63(66.3)$ \\
\cline { 2 - 3 } & Married & $32(33.7)$ \\
\hline \multirow{2}{*}{ Occupation } & Medical Intern & $75(78.9)$ \\
\cline { 2 - 3 } & Physician & $20(21.1)$ \\
\hline \multirow{2}{*}{ Trained about SPs } & Yes & $33(35.5)$ \\
\cline { 2 - 3 } & No & $60(64.5)$ \\
\hline
\end{tabular}

The mean and standard deviations of KAP scores of subjects were $37.6 \pm 7.4$ (out of
46), $32.6 \pm 4.5$ (out of 45 ), and $33.06 \pm 6.5$

(out of 44), respectively (Table 2).

Table 2: The indicative mean and standard deviation of the scores of KAP of SPs

\begin{tabular}{|c|c|c|c|c|}
\hline Variable & Mean \pm SD & The range of scores & Min Scores & Max Scores \\
\hline Knowledge & $37.6 \pm 7.4$ & $0-46$ & 14 & 46 \\
\hline Attitude & $32.6 \pm 4.5$ & $9-45$ & 15 & 45 \\
\hline Practice & $33.06 \pm 6.5$ & $11-44$ & 18 & 44 \\
\hline
\end{tabular}


The independent t-test showed significant differences between knowledge and practice scores and marital status; the score of married subjects was higher than single subjects. The attitude score of married subjects was higher than single subjects, but this difference was not significant. Moreover, significant differences were observed between practice score and training on SPs; the score of trained subjects was higher than untrained subjects. Differences in knowledge and attitude scores were not significant (Table 3).

Table 3: Comparison of mean and standard deviation of the score of KAP of SPs with marital status and training on SPs

\begin{tabular}{|c|c|c|c|c|}
\hline & Variable & & Mean \pm SD & P-value \\
\hline \multirow{4}{*}{ Knowledge } & \multirow{2}{*}{ Marital status } & Single & $36.17 \pm 7.77$ & \multirow{2}{*}{0.01} \\
\hline & & Married & $40.28 \pm 5.70$ & \\
\hline & \multirow{2}{*}{ Training on SPs } & Trained & $37.2 \pm 8.61$ & \multirow{2}{*}{0.89} \\
\hline & & Untrained & $37.4 \pm 6.58$ & \\
\hline \multirow{4}{*}{ Attitude } & \multirow{2}{*}{ Marital status } & Single & $32.24 \pm 4.08$ & \multirow{2}{*}{0.30} \\
\hline & & Married & $32.21 \pm 5.14$ & \\
\hline & \multirow[t]{2}{*}{ Training on SPs } & Trained & $33.12 \pm 4.85$ & \multirow{2}{*}{0.38} \\
\hline & & Untrained & $32.26 \pm 4.32$ & \\
\hline \multirow{4}{*}{ Practice } & \multirow{2}{*}{ Marital status } & Single & $32.00 \pm 6.23$ & \multirow{2}{*}{0.02} \\
\hline & & Married & $35.15 \pm 6.65$ & \\
\hline & \multirow[t]{2}{*}{ Training on SPs } & Trained & $35.45 \pm 6.34$ & \multirow{2}{*}{0.01} \\
\hline & & Untrained & $31.81 \pm 6.39$ & \\
\hline
\end{tabular}

The independent t-test showed significant differences between practice score and training on SPs; the score of subjects trained on SPs was higher than untrained subjects. Nevertheless, this difference was not significant in knowledge and attitude scores.

The independent t-test did not show any significant differences between KAP scores with demographic variables such as age, gender, location of residence, occupation, location of work, and years of health care employment $(\mathrm{P}>0.05)$.

\section{Discussion}

In this study, the response rate was $95 \%$, the mean age of subjects was 27.6 years. The majority of participants were female (62.1\%), single (66.3\%), and medical interns $(78.9 \%)$. In addition, most subjects were untrained on SPs (64.5\%). However, the response rate in the study by Hosoglu was $40.7 \%$, the average age of the respondents was 31.4 years, and the majority were female (63.6\%) (19). The response rate in the study by Melo was $91.1 \%$, the average age of the respondents was 39.6 years, and the majority were female $(91.5 \%)$. In the study by Doebbeling, the response rate was $63 \%$ (8), and in the study by Reda, it was $84.4 \%$ and the mean age of the respondents was 30.8 (7)

The results of this study showed that $35.5 \%$ of subjects had received training on SPs. Abou El-Enein and El Mahdy reported that none of the subjects had received training in the field of infection control (20). Ghofranipour et al. reported that $36.1 \%$ of their study samples had received training on universal precaution prior to their job (21). The results of this research are more satisfactory than those of the study by Abou El-Enein and El Mahdy (20), and Ghofranipour et al (21). The results of this study showed that the knowledge score was desirable but attitude and practice scores were not desirable. In the study by Melo, $75.6 \%$ of subjects 
understood SPs as protective measures and a strategy in daily health care activities (5). In the study by Doebbeling, mean rates of hand washing, avoiding needle recapping, and underreporting sharp injuries were $32-54 \%, 29-70 \%, 22-62 \%$ (overall: $32 \%$ ), respectively. That varied by occupation and adherence to SPs and was found to be suboptimal. Researchers believed that a new strategy for preventing exposures, training, and monitoring adherence was needed (8).

The results of the study by Abou El-Enein and El Mahdy showed that less than half of the nurses $(47.1 \%)$ of a dialysis unit in Alexandria, Egypt, were aware of washing their hands before and after patient care (20).

Cirelli, in his research, in the knowledge evaluation stage reported that only 9 of 29 professionals identified the professional's concept correctly (22). Previous studies have shown that misconceptions persist regarding universal precautions $(16,23$, 24).

Previous studies have shown inadequate adherence to preventive measures, such as recapping needles, routine use of gloves, and hand washing after glove removal (7, $8,25)$.

Results of the study by Amoran and Onwube implied that HCWs had inadequate knowledge about infection control (26). Nevertheless, the results of our research showed a desirable knowledge score.

Our study results emphasized the need for the evaluation of education on infection control practices and SPs in general. Moreover, they highlighted the necessity of performing structured infection control programs among all HCWs such as physicians, and nursing and midwifery staff, and all of the medical sciences students. Our results are in line with the study by Askarian et al., who showed that almost all of the participants reported that they required additional infection control education, especially on standard isolation precautions (27).

Sharma et al., in India, reported that only $50.2 \%$ of HCWs gave correct answers to questions regarding disease transmission through needle stick and sharp injury (28). In general, the results of the current research were similar to those of other studies (28-30).

\section{Conclusion}

Based on the results obtained in this research, educational programs with the foundation of blood-borne infections, infection control, safety recommendations, and different aspects of SPs training program are recommended.

\section{Acknowledgement}

We would like to thank the physicians and medical students who participated in this study, and also the research committee of the Rafsanjan University of Medical Sciences who approved and supported our research. This article is taken from a thesis on medical education.

Conflict of interests: None declared.

\section{References}

1- Oliveira AC, Cardoso CS, Mascarenhas D. Intensive care unit professionals' knowledge and Practice related to the adoption of contact precautions. Rev Lat Am Enfermagem 2009; 17(5):625-31.

2- Askarian M, McLaws ML, Meylan M. Knowledge, attitude, and practices related to standard precautions of surgeons and physicians in university-affiliated hospitals of Shiraz, Iran. Int J Infect Dis 2007; 11(3):213-9.

3- Askarian M, Honarvar B, Tabatabaee HR, Assadian O. Knowledge, practice and attitude towards standard isolation precautions in Iranian medical students. J Hosp Infect 2004; 58(4):292-6.

4- Parmeggiani C, Abbate R, Marinelli P, Angelillo IF. Healthcare workers and health care-associated infections: knowledge, attitudes, and behavior in 
emergency departments in Italy. BMC Infect Dis 2010; 10:35.

5- Melo Dde S, Silva e Souza AC, Tipple AF, das Neves ZC, Pereira MS. Nurses' understanding of standard precautions at a public hospital in Goiania - GO, Brazil. Rev Lat Am Enfermagem 2006; 14(5):720-7.

6- Azap A, Ergönül Ö, Memikoğlu KO, Yeşilkaya A, Altunsoy A, Bozkurt GY, et al. Occupational exposure to blood and body fluids among health care workers in Ankara, Turkey. Am J Infect Control 2005; 33(1):48-52.

7- Reda AA, Fisseha S, Mengistie B, Vandeweerd JM. Standard precautions: occupational exposure and behavior of health care workers in Ethiopia. PloS One 2010; 5(12):e14420.

8- Doebbeling BN, Vaughn TE, McCoy KD, Beekmann SE, Woolson RF, Ferguson $\mathrm{KJ}$, et al. Percutaneous injury, blood exposure, and adherence to standard precautions: Are hospital-based health care providers still at risk. Clin Infect Dis 2003; 37(8):1006-13.

9- Godin G, Naccache H, Morel S, Ebacher MF. Determinants of nurses' adherence to universal precautions for venipunctures. Am J Infect Control 2000; 28(5):359-64.

10- Luo Y, He GP, Zhou JW, Luo Y. Factors impacting compliance with standard precautions in nursing, China. Int J Infect Dis 2010; 14(12):e1106-14.

11- Vossughinia H, Goshayeshi L, Bayegi HR, Sima H, Kazemi A, Erfani S, et al. Prevalence of Hepatitis C Virus Genotypes in Mashhad, Northeast Iran. Iran J Public Health 2012; 41(9):56-61.

12- Moghimi M, Marashi SA, Kabir A, Taghipour HR, Faghihi-Kashani AH, Ghoddoosi I, et al. Knowledge, attitude, and practice of Iranian surgeons about blood-borne diseases. J Surg Res 2009; 151(1):80-4.

13- Pruss-Ustun A, Rapiti E, Hutin Y. Estimation of the global burden of disease attributable to contaminated sharps injuries among health-care workers. Am J Ind Med 2005; 48(6):482-90.

14- Kermode M, Jolley D, Langkham B, Thomas MS, Crofts N. Occupational exposure to blood and risk of bloodborne virus infection among health care workers in rural north Indian health care settings. Am J Infect Control 2005; 33(1):34-41.

15- Zhang M, Wang H, Miao J, Du X, Li T, $\mathrm{Wu} \mathrm{Z}$. Occupational exposure to blood and body fluids among health care workers in a general hospital, China. Am J Ind Med 2009; 52(2):89-98.

16- Kermode M, Jolley D, Langkham B, Thomas MS, Holmes W, Gifford SM. Compliance with Universal/Standard Precautions among health care workers in rural north India. Am J Infect Control 2005; 33(1):27-33.
17- Kabir A, Tabatabaei SV, Khaleghi S, Agah S, Faghihi Kashani AH, Moghimi $\mathrm{M}$, et al. Knowledge, attitudes and practice of Iranian medical specialists regarding hepatitis $\mathrm{B}$ and $\mathrm{C}$. Hepat Mon 2010; 10(3):176-82.

18- Ebrahimi M, Ajami BM, Rezaeian A. Longer years of practice and higher education levels promote infection control in Iranian dental practitioners. Iran Red Crescent Med J 2012; 14(7):422-9.

19- Hosoglu S, Akalin S, Sunbul M, Otkun M, Ozturk R. Predictive factors for occupational bloodborne exposure in Turkish hospitals. Am J Infect Control 2009; 37(1):65-9.

20- Abou El-Enein NY, El Mahdy HM. Standard precautions: a KAP study among nurses in the dialysis unit in a University Hospital in Alexandria, Egypt. J Egypt Public Health Assoc 2011; 86(1-2):3-10.

21- Ghofranipour F, Asadpour M, EftekharArdebili H, Niknami S, Hajizadeh E. Needle Sticks / Sharps Injuries and Determinants in Nursing Care Workers. European Journal of Social Sciences 2009; 11(2):191-7.

22- Cirelli MA, de Figueiredo RM, ZemMascarenhas SH. Adherence to standard precaution in the peripheral vascular access. Rev Lat Am Enfermagem 2007; 15(3):512-4.

23- Kotwal A, Taneja D. Health Care Workers and Universal Precautions: Perceptions and Determinants of Noncompliance. Indian J Community Med 2010; 35(4):526-8.

24- Wu S, Li L, Wu Z, Cao H, Lin C, Yan Z, et al. Universal precautions in the era of HIV/AIDS: perception of health service providers in Yunnan, China. AIDS behav 2008; 12(5):806-14.

25- Hersey JC, Martin LS. Use of infection control guidelines by workers in healthcare facilities to prevent occupational transmission of $\mathrm{HBV}$ and HIV: results from a national survey. Infect Control Hosp Epidemiol 1994; 15(4 Pt 1):243-52.

26- Amoran O, Onwube O. Infection control and practice of standard precautions among healthcare workers in northern Nigeria. J Glob Infect Dis 2013; 5(4):15663

27- Askarian M, Memish ZA, Khan AA. Knowledge, practice, and attitude among Iranian nurses, midwives, and students regarding standard isolation precautions. Infect Control Hosp Epidemiol 2007; 28(2):241-4

28- Sharma S, Gupta A, Arora A. Knowledge, attitude and practices on needle-stick and sharps injuries in tertiary care cardiac hospital: A survey. Indian $\mathrm{J}$ Med Sci 2010; 64(9):396-401.

29- Atif ML, Brenet A, Hageaux S, Fave MH, Cochet C, Baticle E, et al. Awareness of 
standard precautions for 4439 healthcare professionals in 34 institutions in France. Med Mal Infect 2013; 43(1):10-6.

30- Askarian M, Aramesh K, Palenik CJ.
Knowledge, attitude, and practice toward contact isolation precautions among medical students in Shiraz, Iran. Am J Infect Control 2006; 34(9):593-6. 